\title{
Design an Infusion Device Analyzer with Flow Rate Parameters using High Sensitive Photodiode Sensor
}

\author{
Andjar Pudji ${ }^{1}$, Anita Miftahul Maghfiroh ${ }^{1}$, Nuntachai Thongpance ${ }^{2}$ \\ ${ }^{1}$ Department of Electromedical Engineering, Poltekkes Kemenkes Surabaya, Indonesia \\ Jl. Pucang Jajar Timur No. 10, Surabaya, 60245, Indonesia \\ ${ }^{2}$ Biomedical Engineering Department, Rangsit University, Thailand \\ 52/347 Muang-Ake Phaholyothin Road Lak-Hok Muang Pathum Thani 12000, Thailand \\ Email: andjar.pudji@gmail.com, anitamiftah@gmail.com
}

\begin{tabular}{l}
\hline \multicolumn{1}{c}{ Info Artikel } \\
\hline Article History: \\
Received: April 5, 2021 \\
Revision: April 15,2021 \\
Accepted: May 10, 2021
\end{tabular}

Keywords:

Infusion device

calibration

Infusion Device

Analyzer

\begin{abstract}
Abstrak
Infusion devices are the basis for primary health care, that is to provide medicine, nutrition, and hydration to patients. One of the infusion devices is a syringe pump and an infusion pump. This device is very important to assist the volume and flow that enters the patient's body, especially in situations related to neonatology or cancer treatment. Therefore, a comparison tool is needed to see whether the equipment is used or not. The purpose of this research is to make an infusion device analyzer (IDA) design with a flow rate parameter. The contribution of this research is that the tool can calculate the correct value of the flow rate that comes out of the infusion pump and syringe pump. The water released by the infusion pump or syringe pump will be converted into droplets which are then detected by the sensor. This tool uses an infrared sensor and a photodiode. The results obtained by the sensor will come by Arduino nano and code it to the 16x2 Character Liquid Crystal Display (LCD) and can be stored on an SD Card so that it can be analyzed further. In setting the flow rate for the syringe pump of $100 \mathrm{~mL} /$ hour, the error value is $3.9,50 \mathrm{ml} /$ hour $0.02,20 \mathrm{~mL}$ / hour $0.378,10 \mathrm{~mL} /$ hour 0.048 , and $5 \mathrm{~mL}$ / hour 0.01. The results show that the average error of the syringe pump performance read by the module is 0.87. The results obtained from this study can be implemented for the calibration of the infusion pump and the syringe pump so that it can be determined whether the device is suitable or not.
\end{abstract}

This work is an open access article and licensed under a Creative Commons Attribution-ShareAlike 4.0 International License (CC BY-SA 4.0).

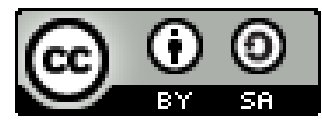

\section{INTRODUCTION}

Infusion devices are the basis for primary health care, that is to provide medicine, nutrition, and hydration to patients. One of the infusion devices is a syringe pump and an infusion pump. This device is very important to assist the volume and flow that enters the patient's body, especially in situations related to neonatology or cancer treatment [1]. The infusion device is used to provide continuous and precise medication indispensable in anesthesia and critical care medicine [2]. Since its introduction for human use in 1950, a remarkable development has occurred regarding this Infusion device which now has a very slick, sophisticated, computer-controlled pump with a digital display that allows us to adjust the infusion rate in milliliters per hour [3]. The infusion device flow rate is always prescribed by the doctor. Nurses and doctors should know the proper drop rate calculations for writing and executing IV fluid treatment orders [4]. Infusion therapy devices can be controlled electronically to provide the correct and measured dose at precisely defined settings [5]. A flow rate controller is provided to adjust the flow rate of the drug connected to the patient by motor drive so that the flow rate becomes constant and minimizes or prevents an increase in the flow rate [6]. However, an electronically controlled motor drive has the potential to cause physiological effects due to the mismatch of the flow rate results used, especially at low flow rate settings [3] [7]. Therefore, the calibration of the infusion device is very important. There are several functions of an infusion device that must be tested to ensure its safety, one of which is the flow rate or flow rate out of the infusion device [8]. In addition, according to Ministry of Health Decree No.54 of 2015 which states that medical devices must be calibrated 


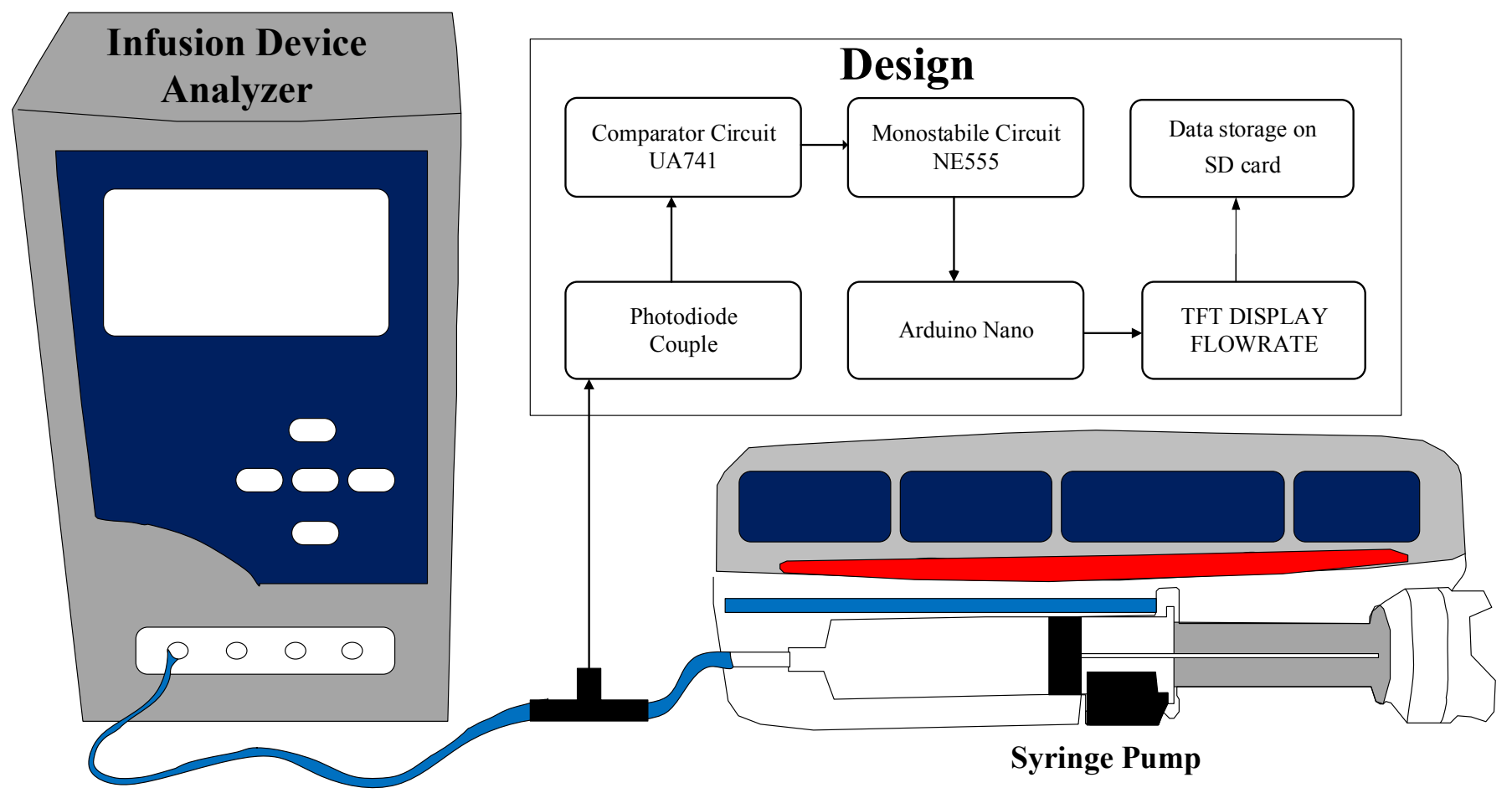

Fig. 1. The experimental setup and the design diagram block

periodically at least once a year [9]. The syringe pump and infusion pump calibration tool is the Infusion Device Analyzer (IDA) which is used to measure the flow rate and occlusion on the appliance. Flow rate measurement using the Infusion Device Analyzer (IDA) is included in measuring the performance of the tool in the calibration of the infusion pump and syringe pump [10].The surprise of flow rate calibration on the infusion pump and syringe pump is needed to measure the flow from the output of the syringe pump and infusion pump which will then be compared with the national standard for unit of measure and the accuracy of the output with the instrument settings.

In 2014 a research was conducted with the title, Design and construction of the infusion device analyzer [11]. This tool uses a load cell sensor to measure the flow rate value. However, this causes the manufacture of this tool to tend to be more expensive. Then a similar research was carried out on the calibration of the infusion device [1][12][13] to find out the true value of the flow rate value. The three studies use various brands of Infusion Device Analyzer which are spread in the market so that doing research requires a lot of money. Then in 2017 a study was made to measure the safety of the syringe pump performance [14]. However, this study only measures its electrical safety. The latest research in 2019 Safira Pintasari has conducted research on the Design of Infusion Pump Analyzer. However, this tool can only take 1 measurement [15]. Nuntachai Thongpance et al, make infusion pump calibrators with the principles of physics, electronics and microcontrollers
[16] consisting of load and pressure sensors. N Thongpance et al, developed a study with a standard calibration curve relationship pattern between the digital output from the load cell to the volume solution, and the pressure acting on the pressure sensor to the digital output [17].

Based on the search results and the above problems, the authors want to improve the infuse device calibration tool by designing an infusion device analyzer equipped with a flow rate sensor. The flow rate sensor here uses an infrared sensor which is used to sense the correct sense of the environment, both radiating infrared radiation [18] and a photodiode with this resistance will decrease according to the affected color. So that the purpose of this research is to know the true value of the flow rate released by the infusion device at a relatively low cost and can take measurements with an unlimited number or according to the maximum volume of the syringe or infusion.

\section{MATERIALS AND METHODS}

\section{A. The system design}

The overall system is depicted in Fig. 1. In this study, the data flow rate was obtained from the output of the Syringe Pump with several settings, that is $100,50,20,10$, and $5 \mathrm{~mL} /$ hour and an infusion pump with a simulation of the measurement test on the infusion pump is carried out with a simulation using a roller clamp on the hose infusion. The roller clamp is set in 3 different conditions, that is the flow rate speed of condition 1 is 


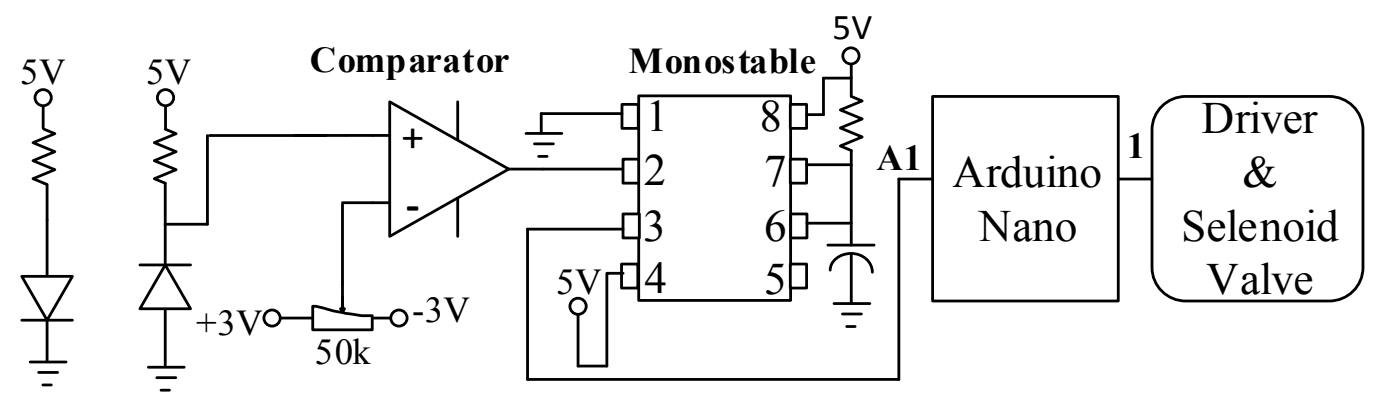

Fig. 3. Electronics connection

faster than condition 2 and the flow rate of condition 2 is faster serving condition 3 .

Block Diagram Fig. e 1. Infrared sensor and photodiode to detect the liquid in the drip chamber of the instrument. The infrared and photodiode output then goes to the comparator frame and is monostable and processed to the Arduino ADC pin. After processing using Arduino, the output is a $2 \times 16$ Character LCD display and stored on the SD Card.

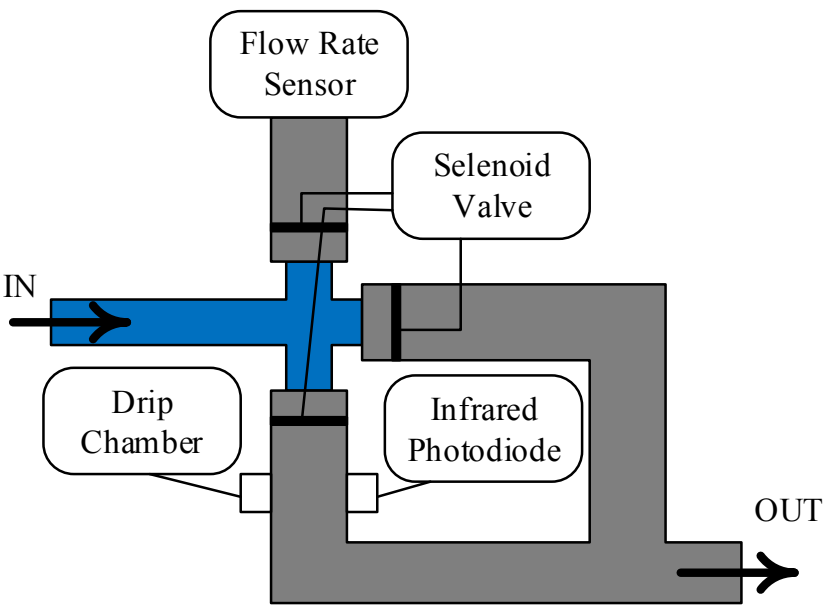

Fig. 2 The Photodiode sensor placement

\section{B. Electronics connection}

The complete system in this study is shown in Fig. e 2. The infuse device will dispense the liquid with the water rate or flow rate according to the setting set at $100 \mathrm{~mL} /$ hour. The liquid that enters the tool will go through the open solenoid valve and the other solenoid valve will be closed, so that the liquid only goes in one direction, namely towards the SKU 237545 pressure sensor shown in Fig. e 3. After the SKU 237545 sensor is pressed by liquid, there is a change in the sensor output in the form of the voltage on the sensor before the liquid is pressed and after being depressed by fluids. The voltage output increases linearly when the liquid presses the SKU 237545 sensor. The output from the SKU 237545 pressure sensor will be connected to the Arduino Nano ADC pin. The program on the Arduino Nano will convert the analog result from the pressure reading to an occlusion value in Psi units. The output of this module is a 16x2 Character LCD display and SD Card.

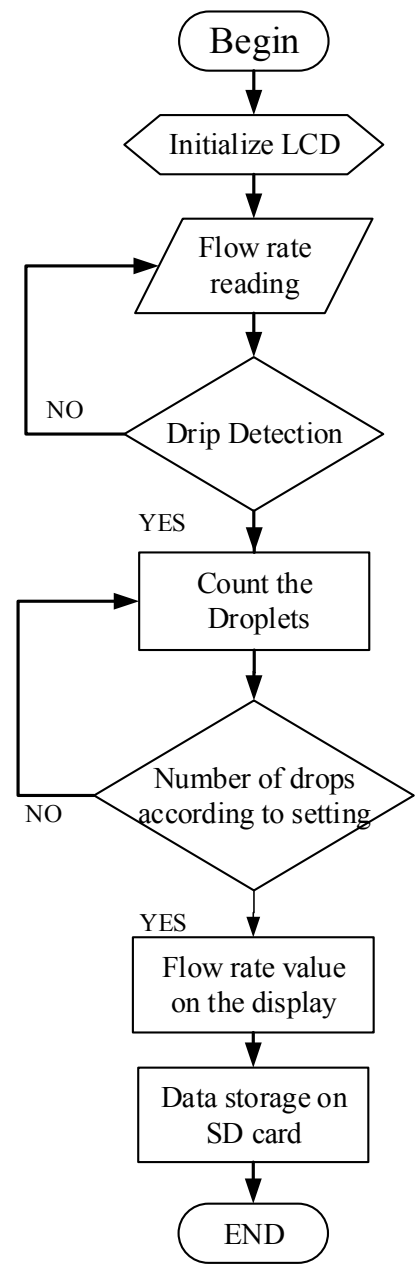

Fig 4. Flow Chart Program Arduino 
The Arduino program is based on a flow chart as shown in Fig. e 4 and illustrated in Algorithm 1. After initialization, a flow rate selection or occlusion will be carried out then the sensor will start reading the droplets which will then be calculated after which Arduino will measure the flow rate value, then the final image will be on the Character LCD 16x2 and saved on SD Card.

\begin{tabular}{|l|l|}
\hline \multicolumn{2}{|c|}{ Algorithm 1: Program Arduino } \\
\hline 1 & BEGIN \\
2 & Initialize LCD \\
3 & Input(settingdrop) \\
4 & IF DripDetection $>0$ THEN \\
5 & ReadFlowRate \\
6 & IF NumberofDrop $>$ SettingDrop THEN \\
7 & CounttheDrop \\
8 & Display(flowrate) \\
9 & Save(Flowrate) \\
10 & END. \\
\hline
\end{tabular}

\section{Result}

In accordance with the purpose of this study is to design an infusion analyzer (IDA) with flow rate parameters. The flow rate of the syringe pump was adjusted to $100 \mathrm{~mL} /$ hour and the error values were $3.9,50 \mathrm{ml} /$ hour $0.02,20 \mathrm{~mL} /$ hour $0.378,10$ $\mathrm{mL} /$ hour 0.048 , and $5 \mathrm{~mL} /$ hour 0.01 . The test results show that the average error of the syringe pump performance read by the module is 0.87 .

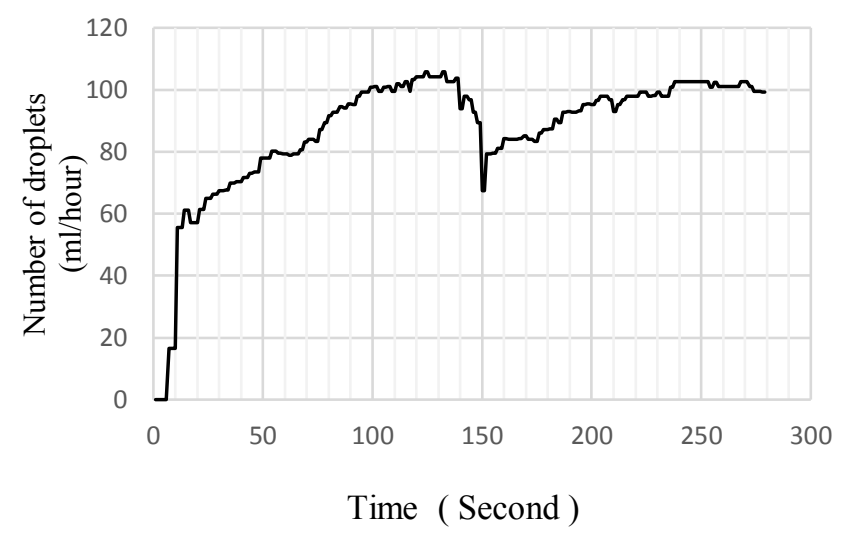

Fig. 5. The response time of the droplet

\section{A. The results of the flow rate parameter test}

This study was used to measure the results of the flow rate performance on the TOP 5300 Syringe Pump. This study was used to measure the results of the flow rate performance on the TOP 5300 Syringe Pump. Fig. E 5 shows the results of the TOP 5300 brand syringe pump test with a flow rate setting of 100 $\mathrm{mL} /$ hour. The results of the graph indicate that the setting on the syringe and the reading on the IDA are still within tolerance limits because the average graph reading is $100 \mathrm{~mL} /$ hour on the rabge.

\section{B. Results of Measurement and Performance Testing of the TOP5300 Syringe Pump}

In testing and measuring the performance of the Syringe Pump, it is carried out to determine the performance of the Infusion Device Analyzer described on Table 1. Data were collected using 5 settings on the Syringe Pump, namely 100, 50, 20,10 , and $5 \mathrm{~mL} /$ hour, where each setting was performed 5 times data collection.

TABLE I. RESULTS OF MEASUREMENT AND PERFORMANCE TESTING OF THE TOP 5300 SYRINGE PUMP BRAND

\begin{tabular}{ccclllll}
\hline $\begin{array}{c}\text { Flow } \\
\text { Set } \\
(\mathrm{mL} / \\
\text { hour })\end{array}$ & $\begin{array}{c}\text { Average } \\
(\mathrm{mL} / \\
\text { hour})\end{array}$ & $\begin{array}{l}\text { Error } \\
(\mathrm{mL} / \\
\text { hour})\end{array}$ & $\begin{array}{l}\text { Standard } \\
\text { Deviation } \\
(\mathrm{mL} /\end{array}$ & $\begin{array}{l}\text { (UA) } \\
(\mathrm{mL} / \\
\text { hour })\end{array}$ & $\begin{array}{l}\text { UB } \\
(\mathrm{mL} / \\
\text { hour })\end{array}$ & $\begin{array}{l}\text { UC } \\
(\mathrm{mL} / \\
\text { hour })\end{array}$ & $\begin{array}{l}\text { U } \\
(\mathrm{mL} / \\
\text { hour})\end{array}$ \\
\hline 100 & 103,9 & 3,9 & 0,122 & 0,054 & 0 & 0,054 & 0,109 \\
\hline 50 & 49,98 & 0,02 & 0,230 & 0,102 & 0 & 0,102 & 0,205 \\
\hline 20 & 20,37 & 0,37 & 0,251 & 0,112 & 0 & 0,112 & 0,225 \\
\hline 10 & 9,952 & 0,04 & 0,074 & 0,033 & 0 & 0,033 & 0,066 \\
\hline 5 & 5,01 & 0,01 & 0,277 & 0,124 & 0 & 0,124 & 0,248 \\
\hline
\end{tabular}

Based on the table above, the average error of the TOP 5300 syringe pump read by the module is 0.87 and the results are not exceeding the tolerance limit so that it can be declared usable.

\section{Results of Measurement and Performance Testing of the Infusion pump Simulation}

In testing and measuring the performance of the infusion pump simulation, it is performed to determine the performance of the Infusion Device Analyzer described on Table 2. The measurement test on the infusion pump is carried out with a simulation using a roller clamp on the hose infusion. The roller clamp is set in 3 different conditions, that is the flow rate speed of condition 1 is faster than condition 2 and the flow rate of condition 2 is faster serving condition 3 .

TABLE II. MEASUREMENT AND TESTING RESULTS OF PUMP INFUSION SIMULATION

\begin{tabular}{ccccccc}
\hline Flow Set & $\begin{array}{c}\text { Average } \\
(\mathrm{mL} / \\
\text { hour })\end{array}$ & $\begin{array}{c}\text { Standard } \\
\text { Deviation } \\
(\mathrm{mL} / \\
\text { hour })\end{array}$ & $\begin{array}{c}\text { (UA) } \\
(\mathrm{mL} / \\
\text { hour })\end{array}$ & $\begin{array}{c}\text { UB } \\
(\mathrm{mL} / \\
\text { hour })\end{array}$ & $\begin{array}{c}\text { UC } \\
(\mathrm{mL} / \\
\text { hour })\end{array}$ & $\begin{array}{c}\text { U } \\
(\mathrm{mL} / \\
\text { hour })\end{array}$ \\
\hline Condition 1 & 279,91 & 1,0024 & 0,4483 & 0 & 0,448 & 0,896 \\
\hline Condition 2 & 137,1 & 4,6770 & 2,0916 & 0 & 2,091 & 4,183 \\
\hline Condition 3 & 105,26 & 1,3352 & 0,5971 & 0 & 0,597 & 1,194 \\
\hline
\end{tabular}


Based on the table above, the infusion pump simulation can be declared usable. However, this is not justified because the Infusion Device Analyzer module is only intended for infusion pumps whose setting values can be adjusted without using a roller clamp.

\section{Statistical Analysis}

Statistical analysis is used to see if there are any significant differences in the measurement settings on the Design and Build an Infusion Device Analyzer with the average measurement results of the TOP5300 syringe pump. The statistical results are shown in Table III describe the same t-test Equal variances to see whether there is a difference between infuse device analyzer design settings and reading on the syringe pump. While Table IV describe the same t-test Unequal Variances to see whether there is a difference between infuse device analyzer design settings and reading on the syringe pump.

TABLE III. T-TEST EQUAL VARIANCES TO SEE IF THERE IS A DIFFERENCE BETWEEN THE INFUSE DEVICE ANALYZER DESIGN SETTINGS AND THE READING ON THE SYRINGE PUMP

\begin{tabular}{lccccc}
\multicolumn{2}{l}{ Equal Variances } & & & & \multicolumn{2}{c}{ Alpha $=0,05$} \\
\hline \hline & std err & $t$-stat & $d f$ & p-value & \multicolumn{1}{c}{-crit } \\
\hline One Tail & 14,248 & 0,005474 & 6 & 0,497904858 & 1,94318 \\
Two Tail & 14,248 & 0,005474 & 6 & 0,995809717 & 2,446912 \\
\hline
\end{tabular}

TABLE IV. T-TEST UNEQUAL VARIANCES TO SEE IF THERE IS A DIFFERENCE BETWEEN THE INFUSE DEVICE ANALYZER DESIGN SETTINGS AND THE READING ON THE SYRINGE PUMP

\begin{tabular}{lccccc}
\multicolumn{2}{l}{ Unequal Variances } & & & \multicolumn{2}{c}{ Alpha $=0,05$} \\
\hline \hline std err & $t$-stat & $d f$ & $p$-value & $t$-crit \\
\hline One Tail & 14,248 & 0,005474 & 5,999 & 0,497904858 & 1,94318 \\
Two Tail & 14,248 & 0,005474 & 5,999 & 0,995809717 & 2,44691 \\
\hline
\end{tabular}

\section{DISCUSSION}

The results of measuring the performance of the Syringe Pump TOP 5300 and the simulation of the infusion pump using the Infusion Device Analyzer (IDA) tool module with Flow rate parameters showing an error value of $3.9,50 \mathrm{ml} /$ hour $0.02,20$ $\mathrm{mL} /$ hour $0.378,10 \mathrm{~mL} /$ hour 0.048 , and $5 \mathrm{~mL} /$ hour 0.01 at setting the flow rate of the syringe pump of $100 \mathrm{~mL} /$ hour. The test results show that the average error of the syringe pump performance read by the module is 0.87 . While the results of the calculation of statistical analysis show that there is no significant difference between the Design and Build an Infusion Device Analysis setting and the calibration results on the syringe pump ( $p$-value $>0.05$ ). These results indicate that the design tool is still at the right level to use.

Nuntachai Thongpance et al, in 2012 found that the proportion of the average error in flow rate measurement and occlusion pressure tests was 0.45 percent and 0.21 percent [16]. Furthermore, Nuntachai Thongpance et al, in 2014 showed that the proportion of the average flow rate error and occlusion pressure was 0.134 percent and 0.132 percent, respectively [17].

The weakness of this research is that the speed of the Syringe Pump or the infusion pump is not stable due to the improper placement of the sensor so that it cannot read the difference when a drop occurs or there is no drop in the drip chamber. Then there is an error in the results caused by air leakage in the mechanics of the tool (hose, hose connection, solenoid valve connection), which affects the results of the calibration.

\section{CONCLUSION}

This study designed and built an infusion analyzer with flow rate parameters by measuring the performance of the TOP 5300 Syringe Pump and infusion pump simulations. The test results show that the average error of the syringe pump performance read by the module is 0.87 . While the results of the calculation of statistical analysis show that there is no significant difference between the Design and Build an Infusion Device Analysis setting and the calibration results on the syringe pump ( $p$ value $>0.05$ ). This shows that this tool can be used as an infusion calibrator such as an infusion pump and a syringe pump. However, this tool needs to be compared with the IDA calibrator to see the error result of the module tool. The tool can be improved by improving the display using a TFT graphic measuring the measurement results that can be accessed directly.

\section{REREFENCES}

[1] E. Batista, J. Alves E Sousa, A. Ribeiro, L. Martins, M. Pereira, and H. Navas, "Calibration of Infusion Pumps Analyser," J. Phys. Conf. Ser., vol. 1065, no. 9, 2018, doi: 10.1088/1742-6596/1065/9/092003.

[2] M. Weiss, S. Gerber, R. M. Füchslin, and T. A. Neff, "Accurate continuous drug delivery at low infusion rate with a novel microvolumetric infusion pump (MVIP): Pump design, evaluation and comparison to the current standard," Anaesthesia, vol. 59, no. 11, pp. 1133-1137, 2004, doi: 10.1111/j.1365-2044.2004.03898.x.

[3] P. A. Lonnqvist, "How continuous are continuous drug infusions?," Intensive Care Med., vol. 26, no. 6, pp. 660-661, 2000, doi: 10.1007/s001340051229.

[4] D. M. Patel, M. V. Patel, K. H. Sharma, J. C. Kaklotar, G. R. Patel, and M. M. Patel, "Efficacy and superiority of an innovative method (IM) of intravenous (IV) fluid drip drop rate calculation using IV set and its comparison with conventional methods (CM)," Int. J. Res. Med. Sci., vol. 7, no. 2, p. 334, 2019, doi: 10.18203/2320-6012.ijrms20190330.

[5] O. Publications, “(12) United States Patent," US 8,798,979 B2, 2014.

\section{Accredited by Ministry of Research and Technology /National Research and Innovation Agency, Indonesia Decree No: 200/M/KPT/2020 \\ Journal homepage: http://ijeeemi.poltekkesdepkes-sby.ac.id/index.php/ijeeemi}


[6] A. Stater, S. Diego, I. P. Law, G. Llp, and T. Coddington, "( 12 ) United States Patent ( 10 ) Patent No .: Assistant Examiner - Megan Anderson," US 8,137,083 B2, 2016.

[7] K. F. Schulze, M. Graff, M. S. Schimmel, A. Schenkman, and P. Rohan, "Physiologic oscillations produced by an infusion pump," J. Pediatr., vol. 103, no. 5, pp. 796-798, 1983, doi: 10.1016/S00223476(83)80489-2.

[8] P. E. Mancene and A. E. Lynch, "Injection Pump Calibrator Device," 5,140,862 US005140862A, 1991.

[9] KEMENTRIAN KESEHATAN, PERMENKES NO 54 TENTANG PENGKALIBRASIAN, vol. 151. 2015.

[10] ECRI, Inspection and Preventive Maintenance System, Procedure/., vol. 1, no. 610. USA: ECRI, 1995.

[11] N. Thongpance N and K. Roongpresent, "Design and Contruction of Infusion Device Analyzer," Biomed. Eng. Int. Conf., pp. 1-5, 2014.

[12] G. Fico, J. Montalva, A. Medrano, N. Liappas, G. Cea, and M. T. Arredondo, "Testing of infusion pumps in healthcare institutions in Bosnia and Herzegovina," vol. 65, pp. 1089-1090, 2018, doi: 10.1007/978-981$10-5122-7$

[13] H. Zhang, H., Bai, Z. and Jiang, "A new detection and analysis of flow rate accuracy on a new tracetype micro-injection drug; pump and syringe pump flow rate accuracy.," China Med. Equip., vol. 13, no. 7, pp. 3133, 2016.

[14] H. K. Tavokali Golpaygani A, Movahedi MM, Reza M, "A study on performance and savety test of infusion pump device," Biomed. Reserch, vol. 28, no. 12, 2017.

[15] I. D. G. H. W. Safira Pintasari, Andjar Pudji, "Rancang Bangun Infusion Pump Analyzer," JEEMI, Vol. 1, No. 1, July 2019.

[16] N. Thongpance, Y. Pititeeraphab, and M. Ophasphanichayakul, "The design and construction of infusion pump calibrator," 5th 2012 Biomed. Eng. Int. Conf. BMEiCON 2012, vol. 100, pp. 3-5, 2012, doi: 10.1109/BMEiCon.2012.6465429.

[17] N. Thongpance and K. Roongprasert, "Design and construction of infusion device analyzer," BMEiCON 2014 - 7th Biomed. Eng. Int. Conf., 2014, doi: 10.1109/BMEiCON.2014.7017377.

[18] P. Ajmera, “A Review Paper on Infrared sensor," Int. J. Eng. Res. Technol., vol. 5, no. 23, pp. 1-3, 2017. 